\title{
Water Quality as a Predictor of Legionella Positivity of Building Water Systems
}

\author{
David Pierre ${ }^{1}{ }^{\circledR}$, Julianne L. Baron ${ }^{1}$, Xiao Ma ${ }^{1}$, Frank P. Sidari III ${ }^{1}$, Marilyn M. Wagener ${ }^{2}$ and \\ Janet E. Stout ${ }^{1,3, *}$ \\ 1 Special Pathogens Laboratory, Pittsburgh, PA 15219, USA; dpierre@specialpathogenslab.com (D.P.); \\ jbaron@specialpathogenslab.com (J.L.B.); maxiaosean1219@gmail.com (X.M.); \\ fsidari@specialpathogenslab.com (F.P.S.III) \\ 2 School of Medicine, University of Pittsburgh, Pittsburgh, PA 15261, USA; mmw5@pitt.edu \\ 3 Department of Civil and Environmental Engineering, University of Pittsburgh, Pittsburgh, PA 15261, USA \\ * Correspondence: jstout@specialpathogenslab.com; Tel.: +1-(412)-281-5335
}

Received: 26 November 2019; Accepted: 11 December 2019; Published: 13 December 2019

\begin{abstract}
Testing drinking water systems for the presence of Legionella colonization is a proactive approach to assess and reduce the risk of Legionnaires' disease. Previous studies suggest that there may be a link between Legionella positivity in the hot water return line or certain water quality parameters (temperature, free chlorine residual, etc.) with distal site Legionella positivity. It has been suggested that these measurements could be used as a surrogate for testing for Legionella in building water systems. We evaluated the relationship between hot water return line Legionella positivity and other water quality parameters and Legionella colonization in premise plumbing systems by testing 269 samples from domestic cold and hot water samples in 28 buildings. The hot water return line Legionella positivity and distal site positivity only demonstrated a $77.8 \%$ concordance rate. Hot water return line Legionella positivity compared to distal site positivity had a sensitivity of $55 \%$ and a specificity of $96 \%$. There was poor correlation and a low positive predictive value between the hot water return line and distal outlet positivity. There was no correlation between Legionella distal site positivity and total bacteria (heterotrophic plate count), $\mathrm{pH}$, free chlorine, calcium, magnesium, zinc, manganese, copper, temperature, total organic carbon, or incoming cold-water chlorine concentration. These findings suggest that hot water return line Legionella positivity and other water quality parameters are not predictive of distal site positivity and should not be used alone to determine the building's Legionella colonization rate and effectiveness of water management programs.
\end{abstract}

Keywords: Legionella; distal site positivity; hot water return line; chlorine; HPC; temperature; water management

\section{Introduction}

Legionella is considered an opportunistic human pathogen and these bacteria have been found in up to $70 \%$ of building water systems [1]. In recent molecular studies, Legionella pneumophila was isolated from $38 \%$ of buildings sampled including $42 \%$ of residences and $35 \%$ of office buildings [2], and in $47 \%$ of all taps in a study of buildings and homes in the United States [3]. Legionella colonization of potable water systems can pose a public health risk, especially for immunocompromised individuals [1,4].

Several organizations including ASHRAE (formerly known as the American Society of Heating, Refrigerating and Air-Conditioning Engineers), the World Health Organization, the American Industrial Hygiene Association, and the Centers for Disease Control and Prevention recommend the creation of water management programs aimed at preventing the growth and spread of Legionella and other waterborne pathogens [5-8]. 
Testing water for the presence of Legionella is the most direct means of determining whether the building water system is colonized by Legionella $[9,10]$ and its usefulness has been discussed in multiple technical guidelines $[7,11,12]$. The correlation with disease risk has been well established in healthcare facilities [13-16], but risk has also been demonstrated in hotels and other commercial properties. Rather than recommend testing for the bacteria, some guidelines and standards have suggested that building design or physical and chemical properties of the water can be used as predictors of risk or to demonstrate that water management programs have effectively controlled the growth and spread of Legionella $[5,8]$.

For example, ASHRAE selected certain physical properties of buildings as requisite characteristics for requiring a water management program [5]. This included building height (greater than 10 stories including below grade), which had previously been found to have an increased presence of Legionella in the buildings' water heaters $[17,18]$. The Centers for Disease Control and Prevention (CDC) and the Centers for Medicare and Medicaid Services (CMS) recommend that temperature, $\mathrm{pH}$, and free chlorine be tested at numerous outlets when doing a Legionella risk assessment $[8,19]$. Others have suggested that the temperature of the hot water in the recirculation line of a building [20] or other water quality parameters could predict the presence or absence of Legionella at the distal outlets (faucets and showers) [20-23].

There is a problem with these recommendations. There is little data to support them. If such monitoring is to be performed and relied upon as part of risk assessments and water management programs, the expectation is that this information will have some relationship to either the presence or absence of Legionella.

It is important that we better understand these assumptions. Therefore, we performed a large-scale field investigation to evaluate the presence of Legionella in premise plumbing systems in 28 buildings in New York City, San Francisco, and New Jersey. The objective of the study was to (1) evaluate the potential of using hot water return line Legionella positivity as an indicator of distal site Legionella colonization risk in these buildings and (2) evaluate the correlation between water quality parameters and the presence of Legionella in water systems.

\section{Results}

\subsection{Legionella Positivity Correlation}

A total of 269 samples were cultured for Legionella from domestic cold and hot water samples in 28 different buildings and from 45 recirculating hot water systems. Legionella was cultured from 65/269 (24.2\%) samples from 15/28 (53.6\%) buildings sampled. The hot water return line sample was positive in $12 / 45(26.7 \%)$ systems (Figure 1). Positive distal sites (faucets) were observed in 20/45 (44.4\%) of the hot water systems. L. pneumophila was the only species of Legionella isolated from these water samples. There was a trend towards larger buildings having more distal site positivity, however this was not statistically significant $(p=0.06)$. 


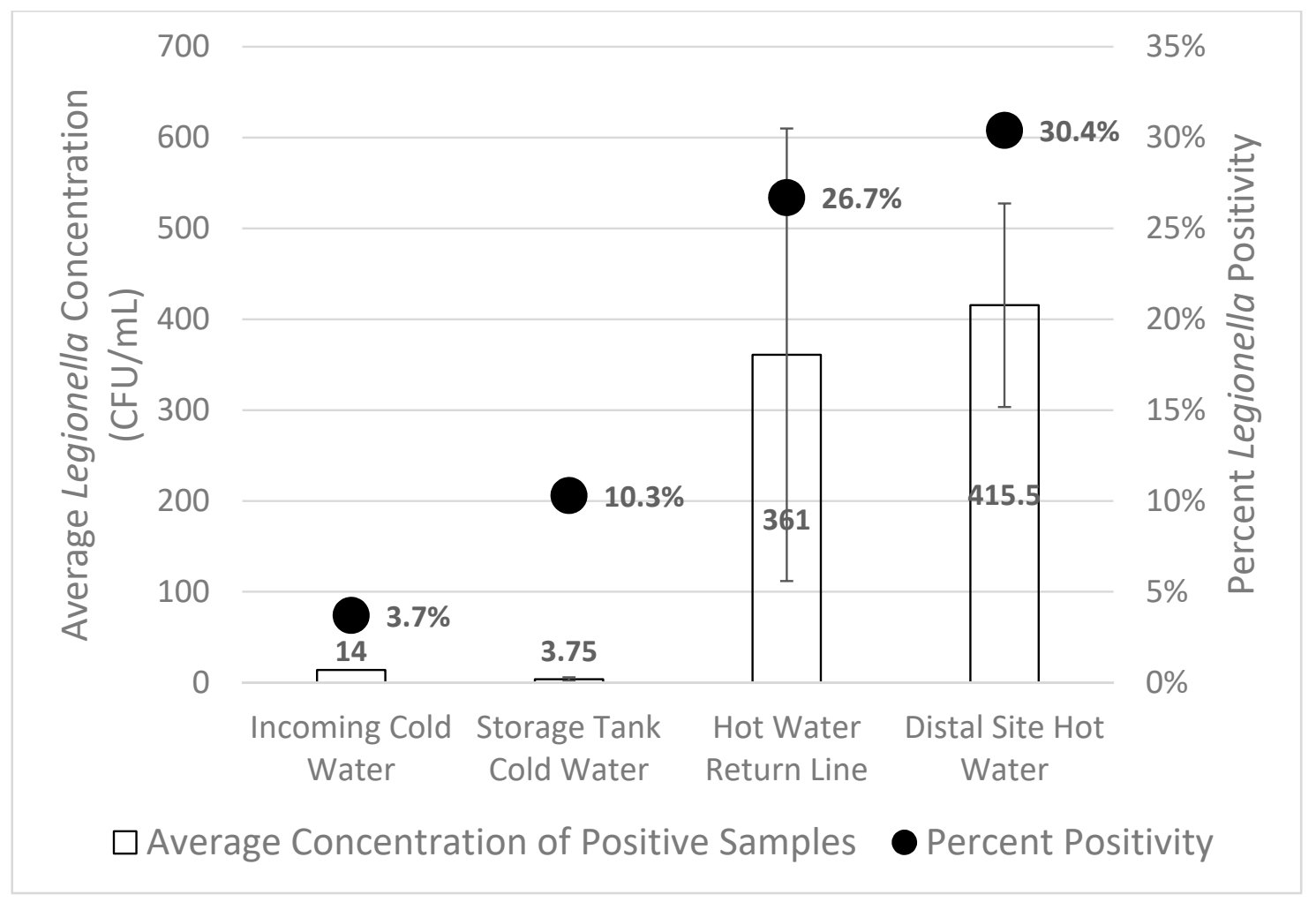

Figure 1. Percent Legionella positivity and concentration was highest in distal site hot water and hot water return lines. The bars represent the standard error of the mean for the average Legionella concentration.

Legionella was isolated from at least one distal site in $91.7 \%$ (11/12) of the hot water systems that also had Legionella isolated from the hot water return line, with an average distal site positivity of $83.3 \%$ $\pm 8.7 \%$ (Figure 2). Legionella was isolated from at least one distal site in $27.3 \%(9 / 33)$ of the hot water systems with a Legionella negative hot water return line, with an average distal site positivity of $13.1 \%$ $\pm 4.3 \%$ (Figure 2). In 35 of the 45 sampled hot water systems, there was agreement between Legionella distal site positivity and hot water return line Legionella positivity, resulting in a $77.8 \%$ concordance rate.

We then analyzed if hot water return line Legionella positivity was able to correctly predict whether the distal sites would be positive or negative for Legionella. Hot water return line positivity was related to distal site positivity $(p=0.002)$, with a sensitivity of only $55 \%(11 / 20)$ and a specificity of $96 \%$ (24/25). However, when hot water return line positivity was used as a screening tool for distal site positivity, the positive predictive value was $91.7 \%$ and the negative predictive value was only $72.7 \%$. The average distal site concentration of Legionella in systems with a positive hot water return was $483.5 \pm 147.4 \mathrm{CFU} / \mathrm{mL}$, versus $20.7 \pm 8.4 \mathrm{CFU} / \mathrm{mL}$ in negative hot water returns $(p<0.003)$ (Figure 2). 


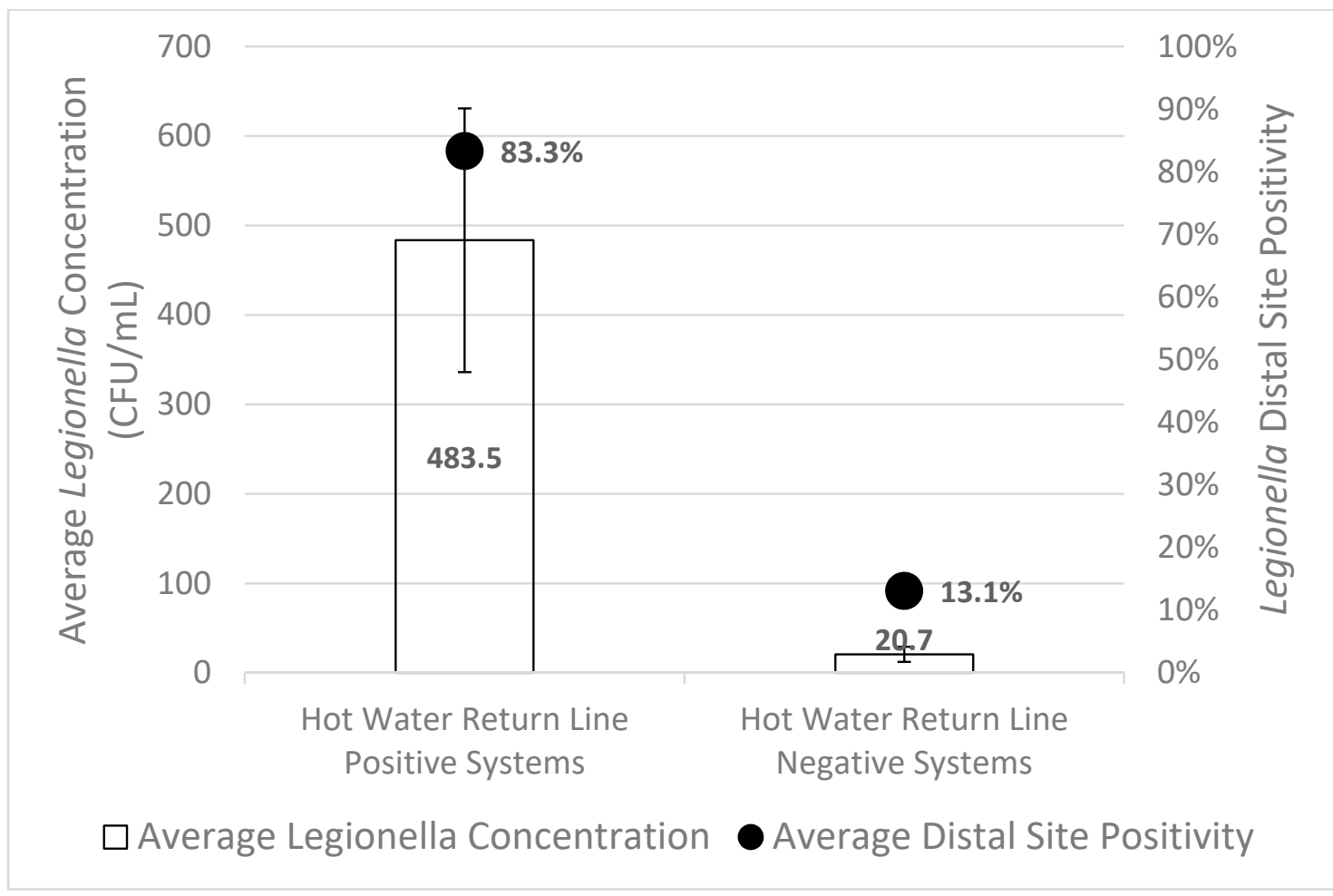

Figure 2. Legionella distal site positivity and concentration was highest for hot water systems with Legionella positive hot water return lines. The bars represent the standard error of the mean for average Legionella concentration.

\subsection{Heterotrophic Plate Count (HPC) and Chemical Parameter Correlation}

All samples collected were also cultured for heterotrophic plate count (HPC) bacteria (Table 1). HPC concentrations in hot water samples ranged from 3 CFU/mL to 2,100,000 CFU/mL. Statistical analysis showed no correlation between distal site HPC concentration and Legionella distal site positivity $(p=0.788)$ (Figure 3). The best-fit linear regression line demonstrates that HPC concentration explains only $0.68 \%$ of the variance in Legionella distal site positivity $\left(R^{2}=0.0068\right)$.

Table 1. Average concentrations ( \pm standard deviation) of total bacteria (heterotrophic plate count-HPC) and physicochemical parameters.

\begin{tabular}{ccccc}
\hline & Incoming Cold Water & Storage Tank Cold Water & Hot Water Return & Distal Site Hot Water \\
\hline HPC $(\mathrm{CFU} / \mathrm{mL})$ & $18,954 \pm 71,478.3$ & $7254 \pm 20,138.3$ & $11,360.4 \pm 25,094.9$ & $92,125.4 \pm 221,547.2$ \\
Temperature $\left({ }^{\circ} \mathrm{F}, 30 \mathrm{~s}\right.$ flush) & $\mathrm{NT}$ & $\mathrm{NT}$ & $\mathrm{NT}$ & $109.36 \pm 21.85$ \\
Temperature $\left({ }^{\circ} \mathrm{F}, 1 \mathrm{~min}\right.$ flush $)$ & $63.12 \pm 9.22$ & $62.66 \pm 9.76$ & $122.80 \pm 17.85$ & $119.95 \pm 73.22$ \\
$\mathrm{pH}$ & $7.29 \pm 0.78$ & $7.17 \pm 0.69$ & $6.97 \pm 0.67$ & $6.93 \pm 0.63$ \\
$\mathrm{Free} \mathrm{Cl}(\mathrm{mg} / \mathrm{L})$ & $0.34 \pm 0.24$ & $0.23 \pm 0.16$ & $0.07 \pm 0.13$ & $0.05 \pm 0.09$ \\
$\mathrm{Fe}(\mathrm{mg} / \mathrm{L})$ & $\mathrm{NA}$ & $\mathrm{NA}$ & $\mathrm{NA}$ & $\mathrm{NA}$ \\
$\mathrm{Ca}(\mathrm{mg} / \mathrm{L})$ & $7.16 \pm 4.41$ & $6.56 \pm 1.58$ & $6.39 \pm 1.19$ & $6.61 \pm 3.09$ \\
$\mathrm{Mg}(\mathrm{mg} / \mathrm{L})$ & $1.66 \pm 1.09$ & $1.46 \pm 0.46$ & $0.72 \pm 1.80$ & $1.79 \pm 1.81$ \\
$\mathrm{Zn}(\mathrm{mg} / \mathrm{L})$ & $0.03 \pm 0.04$ & $0.02 \pm 0.03$ & $\mathrm{NA}$ & $0.04 \pm 0.06$ \\
$\mathrm{~Pb}(\mathrm{mg} / \mathrm{L})$ & $\mathrm{NA}$ & $0.02 \pm 0.02$ & $0.03 \pm 0.12$ & $\mathrm{NA}$ \\
$\mathrm{Mn}(\mathrm{mg} / \mathrm{L})$ & $0.02 \pm 0.03$ & $0.05 \pm 0.06$ & $0.30 \pm 0.51$ & $0.03 \pm 0.11$ \\
$\mathrm{Cu}(\mathrm{mg} / \mathrm{L})$ & $0.09 \pm 0.20$ & $\mathrm{NT}$ & $1.85 \pm 0.26$ & $0.19 \pm 0.23$ \\
$\mathrm{TOC}(\mathrm{mg} / \mathrm{L})$ & $\mathrm{NT}$ & $\mathrm{NT}$ & $\mathrm{NT}$ \\
\hline
\end{tabular}

NA: $48.7 \%$ samples were with Fe concentration below detection limit of $0.03 \mathrm{mg} / \mathrm{L}$, detectable Fe concentration ranged from 0.03 to $4.6 \mathrm{mg} / \mathrm{L} ; 76.2 \%$ samples were with $\mathrm{Pb}$ concentration below detection limit of $0.001 \mathrm{mg} / \mathrm{L} ; \mathrm{Pb}$ concentrations in detectable samples ranged from 0.001 to $0.63 \mathrm{mg} / \mathrm{L}$. NT: not tested. TOC = Total Organic Carbon. 


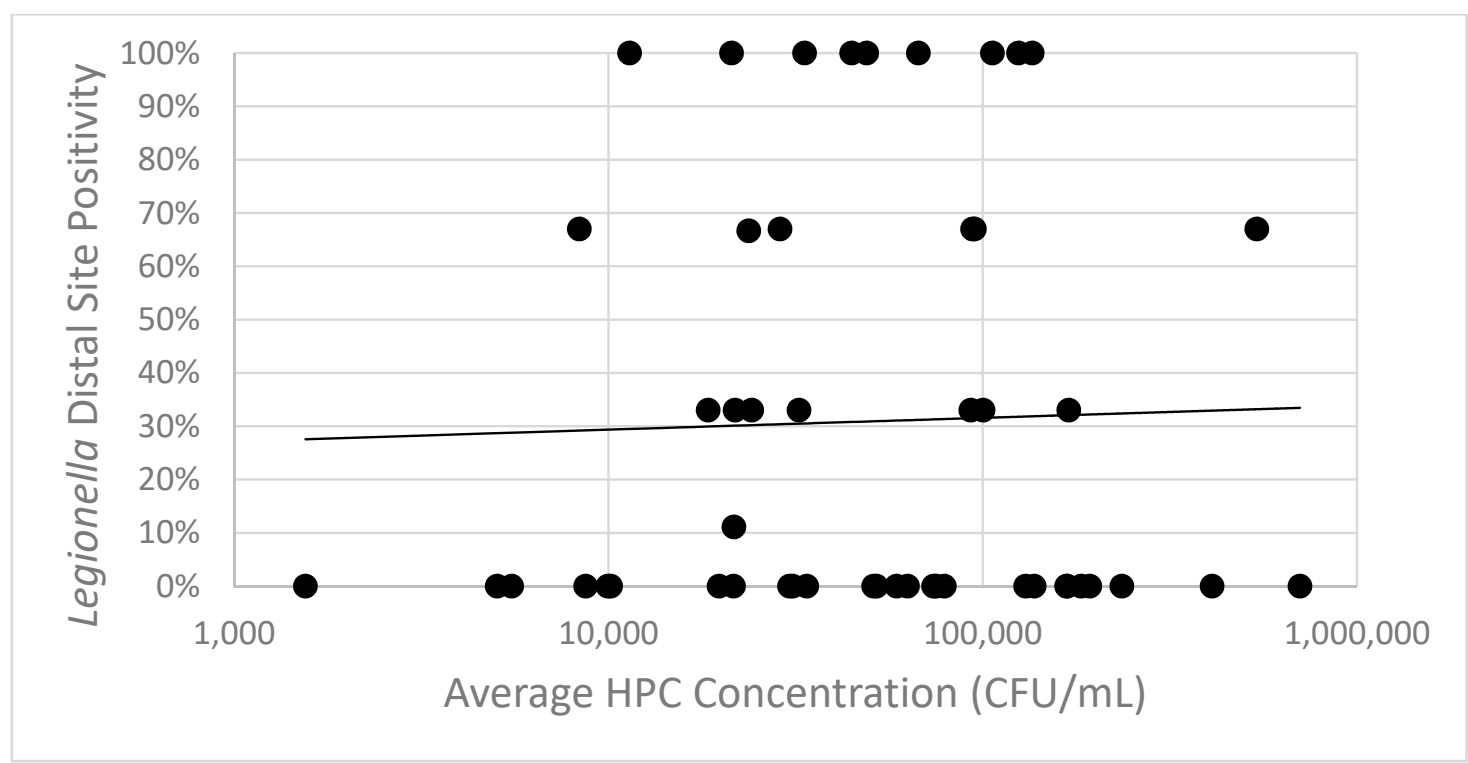

Figure 3. Legionella distal site positivity and average distal site HPC concentration are not significantly associated. Average HPC concentration is represented on a logarithmic scale x-axis. A line of best fit has been added to show the relationship between HPC concentration and distal site positivity.

The water from distal outlets was analyzed for $\mathrm{pH}$, free chlorine, calcium $(\mathrm{Ca})$, magnesium $(\mathrm{Mg})$, zinc $(\mathrm{Zn})$, manganese $(\mathrm{Mn})$, copper $(\mathrm{Cu})$, and TOC. These results were analyzed for correlation with distal site positivity (Table 1). None of the measured parameters were shown to have a correlation with Legionella distal site positivity ( $p$ values $>0.05$ ). Hot water return line $\mathrm{pH}$, free chlorine, calcium, magnesium, zinc, manganese, and copper also were not correlated with Legionella distal site positivity ( $p$ values $>0.05$ ). No comparisons could be made between either distal site or hot water return line iron $(\mathrm{Fe})$ or lead $(\mathrm{Pb})$ concentrations and Legionella distal site positivity because the concentrations were below the lower detection limit of the test method in $49 \%$ and $77 \%$ of samples for iron and lead, respectively.

\subsection{Temperature Correlation}

Distal site temperatures averaged $119.95^{\circ} \mathrm{F}$ after a 1-min flush. Distal site temperature was not statistically related to the distal site Legionella positivity $(p=0.170)$. Distal sites with no Legionella recovered trended towards higher hot water return temperatures, with an average $9.7^{\circ} \mathrm{F}$ higher temperature. However, this was not statistically significant $(p=0.0687)$.

When using $124^{\circ} \mathrm{F}$, the minimum recommended return circulation temperature [24], as a threshold for Legionella distal site positivity, there was an association between the two values $(p=0.013$ ) (Figure 4 ). This hot water return temperature threshold value had a sensitivity of $65 \%(13 / 20)$ and a specificity of $72 \%(18 / 25)$ for determining the Legionella distal site positivity. However, the positive predictive value was only $65 \%(13 / 20)$ and the negative predictive value was $72 \%(18 / 25)$. This recommended temperature threshold is a poor screening test for distal site positivity (receiver operating characteristic $($ ROC) curve area $=0.68)$. In the buildings with a hot water return temperature $>124^{\circ} \mathrm{F}, 28 \%(7 / 25)$ were still positive for Legionella in distal sites. 


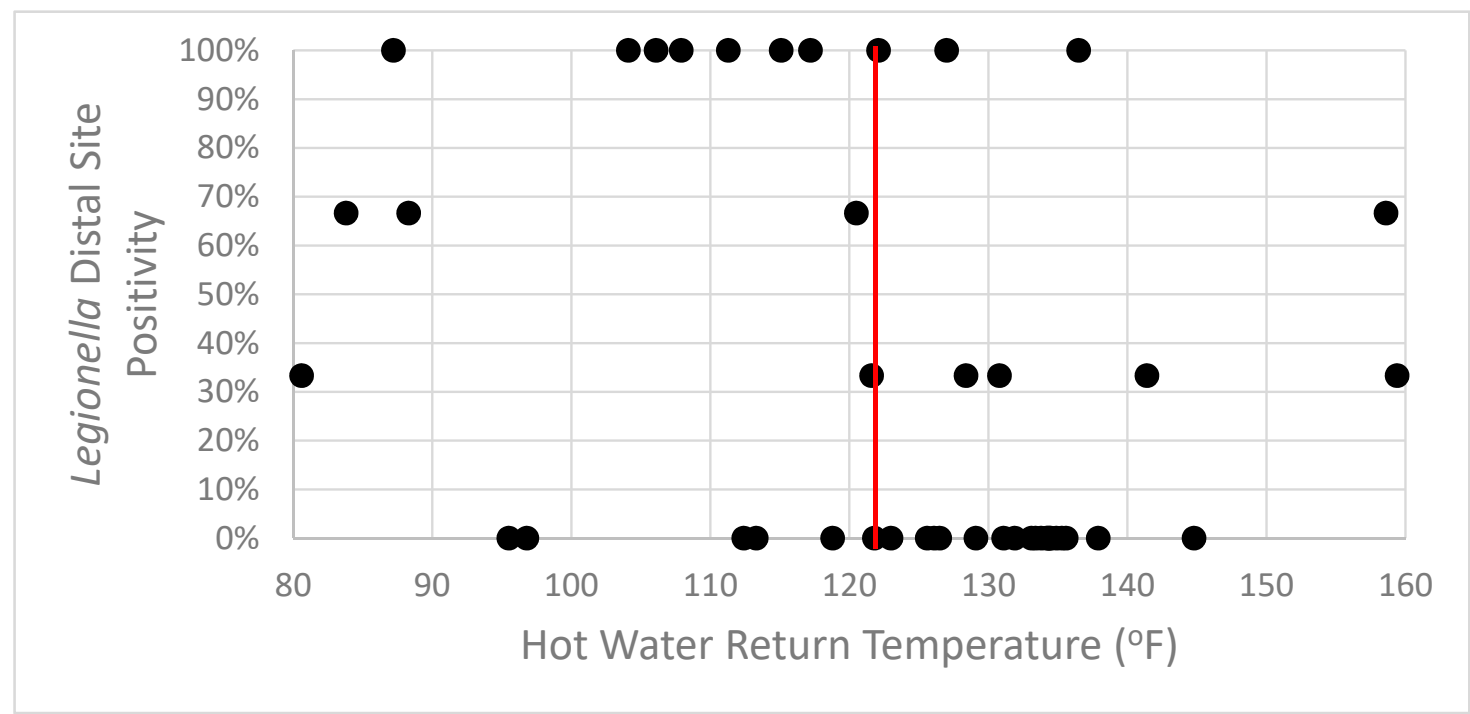

Figure 4. Legionella distal site positivity was seen in systems with hot water return line temperatures above and below the recommended threshold. The red vertical line represents the $124^{\circ} \mathrm{F}$ threshold value.

\subsection{Incoming Cold-Water Chlorine Concentration}

Incoming cold-water chlorine concentration was analyzed to determine if the concentration could be used as a predictor of Legionella distal site positivity. Incoming cold-water chlorine measurements were available from 20 buildings. Using $0.5 \mathrm{mg} / \mathrm{L}$ as the threshold for the acceptable level of free residual chlorine found in drinking water [25], there was no correlation between incoming chlorine concentration and Legionella positivity $(p=0.582)$ (Figure 5). This $0.5 \mathrm{mg} / \mathrm{L}$ incoming chlorine threshold fails as a screening tool for Legionella distal site positivity ( $\mathrm{ROC}$ curve area $=0.47$ ).

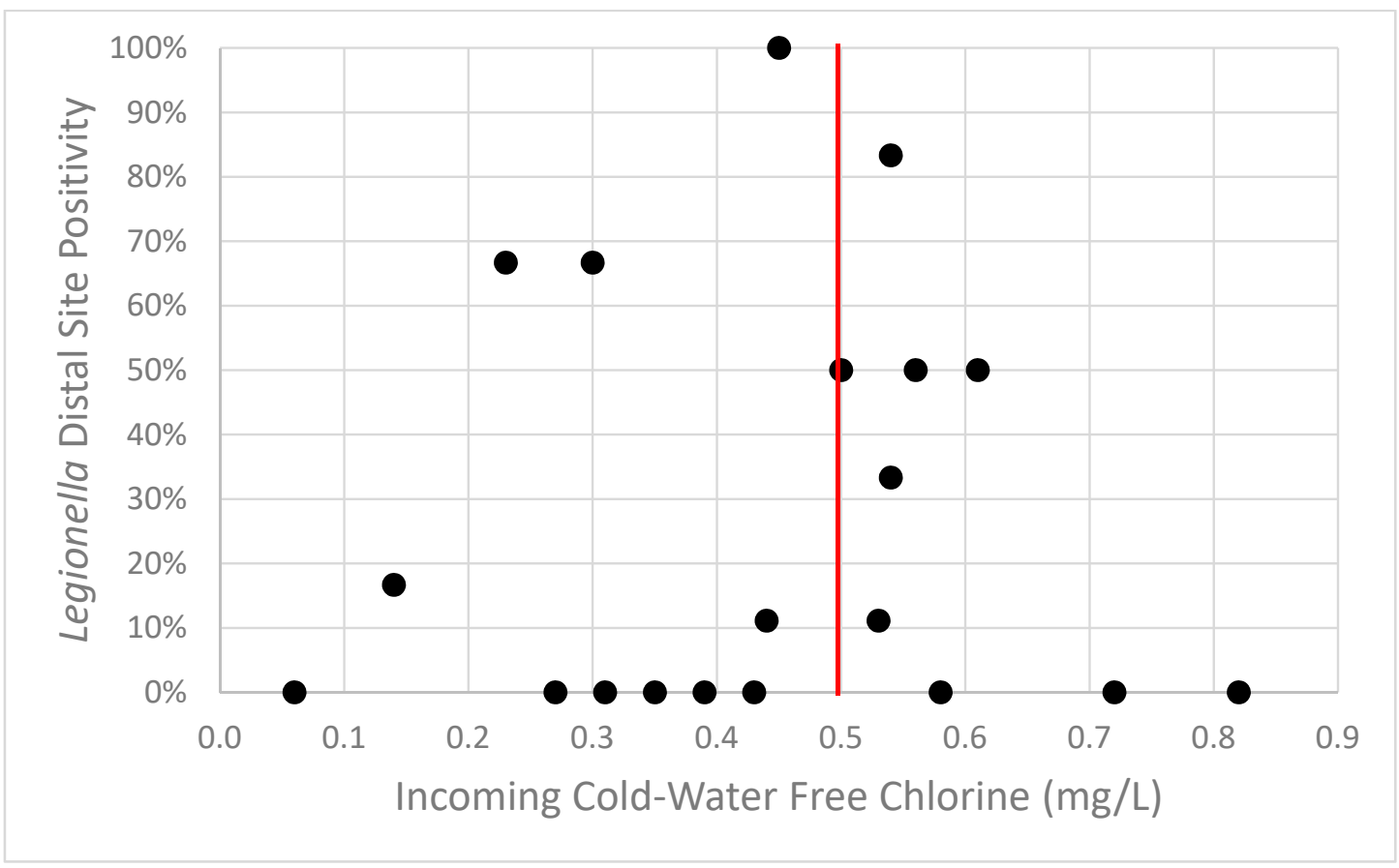

Figure 5. Legionella distal site positivity was seen in buildings with incoming cold-water free chlorine above and below the recommended threshold. The red vertical line represents the $0.5 \mathrm{mg} / \mathrm{L}$ threshold value. 


\section{Discussion}

Public health agencies and some guidance documents recommend monitoring temperature and water quality parameters as part of Legionella risk assessments and water management programs. A reasonable assumption in following these recommendations is that there is some relationship to Legionella presence or absence.

However, few studies have been conducted to evaluate these relationships and to determine if any of these surrogate measurements can substitute for Legionella sampling in assessing risk or effectiveness of control measures [20-23] and there is a growing interest for a more efficient sampling approach for water system Legionella testing $[20,26]$. In this study we measured Legionella positivity, heterotrophic plate count bacteria, and other water physicochemical parameters, including temperature, free chlorine concentration, $\mathrm{pH}$, calcium, magnesium, total organic carbon, iron, zinc, lead, manganese, and copper concentrations. We also evaluated the correlation between hot water return line Legionella positivity or these other water quality parameters to determine if any of these relationships were predictive of Legionella distal site positivity.

Our analysis showed that the concordance rate between hot water return line Legionella positivity and distal site Legionella positivity was $77.8 \%$. This was similar to a previous report of $79 \%$ concordance between the hot water recirculation loop and distal sites [20]. In the current study, we further determined the sensitivity and specificity of using hot water return line Legionella positivity as a screening tool to predict distal site Legionella positivity. The low sensitivity (55\%) indicates a low probability of finding distal site Legionella colonization based on the hot water return line Legionella positivity alone. In many cases, hot water return lines that yielded no Legionella had positive distal sites in that system.

Studies have linked the presence of Legionella in building water systems to water physicochemical parameters such as trace elements concentration, $\mathrm{pH}$, and temperature. A significant association between Legionella presence and concentrations of $\mathrm{Mn}, \mathrm{Zn}$, and Fe was reported previously [22]. In another report, iron was significantly higher (average $1.43 \mathrm{mg} / \mathrm{L}$ ) in Legionella positive public building water samples compared to Legionella negative samples (average $0.09 \mathrm{mg} / \mathrm{L}$ ) [27]. This association was also seen with residential water systems [28]. In the present study, statistical analysis of the correlation between Legionella positivity and $\mathrm{Fe}$ as well as $\mathrm{Pb}$ concentration was not possible, because $49 \%$ and $77 \%$ of total samples had $\mathrm{Fe}$ and $\mathrm{Pb}$ concentrations lower than the lower detection limit (0.06 and $0.002 \mathrm{mg} / \mathrm{L}$, respectively). Copper concentrations of $>0.05 \mathrm{mg} / \mathrm{L}$ have been associated with a lower risk of Legionella colonization [29].

We observed no statistically significant correlation between distal site Legionella positivity and $\mathrm{HPC}$, temperature, $\mathrm{pH}$, free chlorine (incoming cold water and distal site), $\mathrm{Ca}, \mathrm{Mg}, \mathrm{Zn}, \mathrm{Mn}, \mathrm{Cu}$, and hot water return TOC. We found HPC concentration to be a poor predictor of Legionella positivity. HPC concentration was only able to explain $0.68 \%$ of the variation in Legionella distal site positivity. These results are consistent with a previous report that also showed the lack of correlation between total bacterial counts, measured by HPC, and Legionella colonization [23].

Legionella negative hot water systems trended towards higher temperature, Ca concentration, and lower hot water return TOC concentration, however, these were not statistically significant. In contrast to one other study, we found no correlation between Legionella colonization and manganese in building water systems [30]. Legionella positive systems trended towards higher Mn concentration on average, although this relationship was also not statistically significant.

From our experience, buildings $>10$ stories high often have multiple centralized hot water systems installed to serve different building zones. The complexity of these centralized hot water systems lead to favorable environments for Legionella colonization, such as increased water age, favorable temperatures, and a lack of disinfectant residual $[2,18,27,31,32]$. Previous studies have shown a correlation between the building size and Legionella growth. These studies have indicated that larger buildings ( $>10$ stories) and those with centralized hot water systems are more likely to support Legionella growth $[17,18]$. 
We did not see a statistical relationship in our study, between building size and Legionella positivity, however our data suggest the need for further investigation with larger data sets.

The risk of acquiring Legionnaires' disease has been previously associated with high levels of distal site Legionella positivity $(>30 \%)$ [1,9,13-15]. Localized Legionella colonization at the point-of-use such as faucets and shower heads had been frequently observed and linked to the risk of susceptible individuals [33-35] and would serve as a patient-water system interaction point. Monitoring a facility's water system for Legionella colonization involves sampling distal hot water outlets regularly, which may necessitate the collection of numerous samples, especially for large facilities with multiple hot water systems $[6,20]$.

Based on our study, sampling and culturing only the hot water return lines for Legionella presence demonstrates a low sensitivity of identifying Legionella colonization and therefore Legionnaires' disease risk. Similarly, the measured water quality parameters were not predictors of Legionella distal site positivity. Hot water temperature or incoming cold-water chlorine thresholds, $124^{\circ} \mathrm{F}$ and $0.5 \mathrm{mg} / \mathrm{L}$, respectively, also did not serve as good screening tools for Legionella colonization. In facilities with high risk residents, such as hospitals and long-term care facilities, a more conservative approach of direct sampling of at least 10 distal sites is recommended [9,36,37]. Based on our results, we recommend that in lower risk facilities, such as commercial or administrative buildings, sampling at least three distal sites and the hot water return should be done for routine surveillance in each hot water system. If positive samples are found, a more thorough examination of the extent and location of colonization may be warranted especially in office buildings where Legionella has been found to persist regardless of building age [2]. In ASHRAE Standard 188, an important part of any water management program is to ensure that there is validation of the program's efficacy. This is to ensure the water management program is controlling identified hazardous conditions, specifically the risk of Legionella growth and spread. Our results demonstrate that these surrogate measurements cannot be used to validate the control of Legionella risk at a facility because they are not predictive of the presence or absence of Legionella species.

\section{Materials and Methods}

\subsection{Sample Collection and Onsite Water Quality Parameter Measurements}

Bulk water samples were collected from 28 buildings in New York City ( 25 buildings), San Francisco (two buildings), and New Jersey (one building) from March to September 2015. The sampled buildings included commercial buildings ranging from 5 to 57 floors. Samples were collected from the incoming cold-water per building, cold-water storage tank per cold water system, three hot water distal outlets per hot water system (near, mid and far), and the hot water return line from each hot water system.

Cold water and hot water return line samples were collected after a 1-min flush. A $1 \mathrm{~L}$ sample with sodium thiosulfate for microbiological analyses and a $250 \mathrm{~mL}$ sample preserved with nitric acid for metal analyses (iron (Fe), copper $(\mathrm{Cu})$, lead $(\mathrm{Pb})$, zinc $(\mathrm{Zn})$, calcium $(\mathrm{Ca})$, magnesium $(\mathrm{Mg})$, and manganese $(\mathrm{Mn})$ ) were collected. Hot water distal outlet samples were collected and treated as above, but the $1 \mathrm{~L}$ microbiological sample was taken prior to flushing. Additionally, for hot water return line samples, two $50 \mathrm{~mL}$ vials with hydrochloric acid preservative were collected for total organic carbon (TOC) testing. Measurements for temperature, $\mathrm{pH}$, and free chlorine were conducted onsite after sample collection.

Temperature, $\mathrm{pH}$, and free chlorine residual concentration were measured on-site at the time of sample collection using a digital thermometer, portable Hach 900 colorimeter, and Oakton Acorn $\mathrm{pH}$ meter following the manufacturer's protocols. Samples for microbiological analyses were shipped on ice overnight to Special Pathogens Laboratory (Pittsburgh, PA, USA) and samples for metal analyses and total organic carbon testing were shipped to ALS Environmental (Middletown, PA, USA). 


\subsection{Microbiological Analyses}

Legionella culture was conducted using buffered charcoal yeast extract agar (BCYE) (Remel, Lenexa, KS, USA) and selective media supplemented with glycine, vancomycin, and polymyxin B (DGVP) [38] using a modified ISO method $[39,40]$. Heterotrophic plate count (HPC) bacteria culture was performed using R2A agar (Remel, Lenexa, KS, USA) following standard method 9215B [41]. Culture media plates were prepared in-house with dehydrated media as noted above.

\subsection{Statistical Analyses}

For categorical data (building size, dichotomized threshold variables) Legionella positivity was compared using the Chi square test. Logistic models were used to evaluate Legionella positivity (presence/absence) and continuous variables (HPC, temperature, $\mathrm{pH}$, free chlorine, calcium, magnesium, zinc, manganese, copper, and total organic carbon). A receiver operating characteristic (ROC) curve and the area under the curve (AUC) were generated to evaluate the utility of hot water return line temperature (dichotomized by recommended threshold) for predicting Legionella positivity. All statistics were performed using Stata version 13.0 (Stata Corp, College Station, TX, USA). A linear regression, and resulting $\mathrm{R}^{2}$ value, was generated to evaluate the utility of HPC concentration for predicting Legionella positivity using Microsoft Excel.

\section{Conclusions}

Water quality measurements, including hot water return line Legionella positivity, total bacterial counts, temperature, and other physicochemical parameters, have previously been sought or suggested as alternative approaches to determine the Legionella risk for a building's water system instead of directly culturing the system. We found a concordance rate of only $77.8 \%$ between hot water return Legionella positivity and distal site Legionella positivity. Additionally, using hot water return line positivity as a predictor for Legionella distal site positivity had a sensitivity of only $55 \%$ and a specificity of $96 \%$. There was no significant correlation between Legionella positivity and any water quality parameter (HPC, temperature, incoming cold-water chlorine, or physicochemical concentrations) tested. Neither hot water return line Legionella positivity nor other water quality parameters are suitable as a surrogate or stand-alone replacement for sampling and culturing distal sites for Legionella colonization in building water systems, especially in facilities with higher-risk populations.

Author Contributions: Conceptualization, F.P.S.III and J.E.S.; formal analysis, J.L.B., X.M., and M.M.W.; investigation, D.P. and X.M.; writing - original draft preparation, D.P., J.L.B. and X.M.; writing-review and editing, D.P., J.L.B., X.M., F.P.S.III, M.M.W., and J.E.S.; visualization, D.P. and J.L.B.; supervision, F.P.S.III and J.E.S.

Funding: This research received no external funding.

Conflicts of Interest: The authors declare no conflict of interest.

\section{References}

1. Stout, J.E.; Yu, V.L.; Muraca, P.; Joly, J.; Troup, N.; Tompkins, L.S. Potable Water as a Cause of Sporadic Cases of Community-Acquired Legionnaires' Disease. N. Engl. J. Med. 1992, 326, 151-155. [CrossRef] [PubMed]

2. Donohue, M.J.; King, D.; Pfaller, S.; Mistry, J.H. The sporadic nature of Legionella pneumophila, Legionella pneumophila Sg1 and Mycobacterium avium occurrence within residences and office buildings across 36 states in the United States. J. Appl. Microbiol. 2019, 126, 1568-1579. [CrossRef] [PubMed]

3. Donohue, M.J.; O'Connell, K.; Vesper, S.J.; Mistry, J.H.; King, D.; Kostich, M.; Pfaller, S. Widespread Molecular Detection of Legionella pneumophila Serogroup 1 in Cold Water Taps across the United States. Environ. Sci. Technol. 2014, 48, 3145-3152. [CrossRef] [PubMed]

4. Anaissie, E.J.; Penzak, S.R.; Dignani, M.C. The hospital water supply as a source of nosocomial infections: A plea for action. Arch. Intern. Med. 2002, 162, 1483-1492. [CrossRef]

5. ASHRAE. ANSI/ASHRAE Standard 188-2018. In Legionellosis: Risk Management for Building Water Systems; American Society of Heating, Refrigerating and Air-Conditioning Engineers: Atlanta, GA, USA, 2018. 
6. World Health Organization (WHO). Legionella and the Prevention of Legionellosis; WHO: Geneva, Switzerland, 2007.

7. AIHA. Recognition, Evaluation, and Control of Legionella in Building Water Systems; American Industrial Hygiene Association: Falls Church, VA USA, 2015.

8. Centers for Disease Control and Prevention (CDC). Developing a Water Management Program to Reduce Legionella Growth \& Spread in Buildings-A Practical Guide to Implementing Industry Standards; US Department of Health and Human Services: Atlanta, GA, USA, 2017.

9. Stout, J.E.; Yu, V.L. Environmental culturing for Legionella: Can we build a better mouse trap? Am. J. Infect. Control 2010, 38, 341-343. [CrossRef]

10. Stout, J.E.; Muder, R.R.; Mietzner, S.; Wagener, M.M.; Perri, M.B.; DeRoos, K.; Goodrich, D.; Arnold, W.; Williamson, T.; Ruark, O.; et al. Role of environmental surveillance in determining the risk of hospital-acquired legionellosis: A national surveillance study with clinical correlations. Infect. Control Hosp. Epidemiol. Off. J. Soc. Hosp. Epidemiol. Am. 2007, 28, 818-824. [CrossRef]

11. Kozak, N.A.; Lucas, C.E.; Winchell, J.M. Identification of Legionella in the Environment. In Legionella: Methods and Protocols; Buchrieser, C., Hilbi, H., Eds.; Humana Press: Totowa, NJ, USA, 2013; pp. 3-25. [CrossRef]

12. ASTM. D5952-08(2015), Standard Guide for the Inspection of Water Systems for Legionella and the Investigation of Possible Outbreaks of Legionellosis (Legionnaires' Disease or Pontiac Fever); ASTM International: West Conshohocken, PA, USA, 2015.

13. Best, M.; Yu, V.L.; Stout, J.; Goetz, A.; Muder, R.R.; Taylor, F. Legionellaceae in the hospital water supply-epidemiological link with disease and evaluation of a method of control of nosocomial Legionnaires' disease and Pittsburgh pneumonia. Lancet 1983, 2, 307-310. [CrossRef]

14. Kool, J.L.; Bergmire-Sweat, D.; Butler, J.C. Hospital characteristics associated with colonization of water systems by Legionella and risk of nosocomial legionnaires' disease: A cohort study of 15 hospitals. Infect. Control Hosp. Epidemiol. 1999, 20, 798-805. [CrossRef]

15. Sabria, M.; Modol, J.M.; Garcia-Nunez, M.; Reynaga, E.; Pedro-Botet, M.L.; Sopena, N. Environmental cultures and hospital-acquired Legionnaires' disease: A 5-year prospective study in 20 hospitals in Catalonia, Spain. Infect. Control Hosp. Epidemiol. Off. J. Soc. Hosp. Epidemiol. Am. 2004, 25, 1072-1076. [CrossRef]

16. Boccia, S.; Laurenti, P.; Borella, P.; Moscato, U.; Capalbo, G.; Cambieri, A.; Amore, R.; Quaranta, G.; Boninti, F.; Orsini, M.; et al. Prospective 3-year surveillance for nosocomial and environmental Legionella pneumophila: Implications for infection control. Infect. Control Hosp. Epidemiol. Off. J. Soc. Hosp. Epidemiol. Am. 2006, 27, 459-465. [CrossRef]

17. Flannery, B.; Gelling, L.B.; Vugia, D.J.; Weintraub, J.M.; Salerno, J.J.; Conroy, M.J.; Stevens, V.A.; Rose, C.E.; Moore, M.R.; Fields, B.S.; et al. Reducing Legionella colonization in water systems with monochloramine. Emerg. Infect. Dis. 2006, 12, 588-596. [CrossRef] [PubMed]

18. Borella, P.; Montagna, M.T.; Romano-Spica, V.; Stampi, S.; Stancanelli, G.; Triassi, M.; Neglia, R.; Marchesi, I.; Fantuzzi, G.; Tato, D.; et al. Legionella infection risk from domestic hot water. Emerg. Infect. Dis. 2004, 10, 457-464. [CrossRef] [PubMed]

19. Wright, D.R.; Centers for Medicare \& Medicaid Services. Requirement to Reduce Legionella Risk in Healthcare Facility Water Systems to Prevent Cases and Outbreaks of Legionnaires' Disease (LD). In SEC 17-30-Hospitals/CAHs/NHs; Department of Health \& Human Services: Baltimore, MD, USA, 2017.

20. Ditommaso, S.; Giacomuzzi, M.; Gentile, M.; Moiraghi, A.R.; Zotti, C.M. Effective environmental sampling strategies for monitoring Legionella spp contamination in hot water systems. Am. J. Infect. Control 2010, 38, 344-349. [CrossRef]

21. Bédard, E.; Fey, S.; Charron, D.; Lalancette, C.; Cantin, P.; Dolcé, P.; Laferrière, C.; Déziel, E.; Prévost, M. Temperature diagnostic to identify high risk areas and optimize Legionella pneumophila surveillance in hot water distribution systems. Water Res. 2015, 71, 244-256. [CrossRef] [PubMed]

22. Bargellini, A.; Marchesi, I.; Righi, E.; Ferrari, A.; Cencetti, S.; Borella, P.; Rovesti, S. Parameters predictive of Legionella contamination in hot water systems: Association with trace elements and heterotrophic plate counts. Water Res. 2011, 45, 2315-2321. [CrossRef]

23. Duda, S.; Baron, J.L.; Wagener, M.M.; Vidic, R.D.; Stout, J.E. Lack of correlation between Legionella colonization and microbial population quantification using heterotrophic plate count and adenosine triphosphate bioluminescence measurement. Environ. Monit. Assess. 2015, 187, 393. [CrossRef] 
24. ASHRAE. ASHRAE Guideline 12-2000. In Minimizing the Risk of Legionellosis Associated with Building Water Systems; American Society of Heating, Refrigerating and Air-Conditioning Engineers: Atlanta, GA, USA, 2000.

25. World Health Organization (WHO). Guidelines for Drinking-Water Quality; WHO: Geneva, Switzerland, 2011.

26. Wang, H.; Bédard, E.; Prévost, M.; Camper, A.K.; Hill, V.R.; Pruden, A. Methodological approaches for monitoring opportunistic pathogens in premise plumbing: A review. Water Res. 2017, 117, 68-86. [CrossRef]

27. Edagawa, A.; Kimura, A.; Doi, H.; Tanaka, H.; Tomioka, K.; Sakabe, K.; Nakajima, C.; Suzuki, Y. Detection of culturable and nonculturable Legionella species from hot water systems of public buildings in Japan. J. Appl. Microbiol. 2008, 105, 2104-2114. [CrossRef]

28. Stout, J.E.; Yu, V.L.; Yee, Y.C.; Vaccarello, S.; Diven, W.; Lee, T.C. Legionella pneumophila in residential water supplies: Environmental surveillance with clinical assessment for Legionnaires' disease. Epidemiol. Infect. 1992, 190, 49-57.

29. Leoni, E.; De Luca, G.; Legnani, P.P.; Sacchetti, R.; Stampi, S.; Zanetti, F. Legionella waterline colonization: Detection of Legionella species in domestic, hotel and hospital hot water systems. J. Appl. Microbiol. 2005, 98, 373-379. [CrossRef]

30. Kehres, D.G.; Maguire, M.E. Emerging themes in manganese transport, biochemistry and pathogenesis in bacteria. Fems Microbiol. Rev. 2003, 27, 263-290. [CrossRef]

31. Rhoads, W.J.; Pruden, A.; Edwards, M.A. Convective Mixing in Distal Pipes Exacerbates Legionella pneumophila Growth in Hot Water Plumbing. Pathogens 2016, 5, 29. [CrossRef]

32. Serrano-Suarez, A.; Dellunde, J.; Salvado, H.; Cervero-Arago, S.; Mendez, J.; Canals, O.; Blanco, S.; Arcas, A.; Araujo, R. Microbial and physicochemical parameters associated with Legionella contamination in hot water recirculation systems. Environ. Sci. Pollut. Res. 2013, 20, 5534-5544. [CrossRef]

33. Halabi, M.; Wiesholzer-Pittl, M.; Schoberl, J.; Mittermayer, H. Non-touch fittings in hospitals: A possible source of Pseudomonas aeruginosa and Legionella spp. J. Hosp. Infect. 2001, 49, 117-121. [CrossRef]

34. Hosein, I.K.; Hill, D.W.; Tan, T.Y.; Butchart, E.G.; Wilson, K.; Finlay, G.; Burge, S.; Ribeiro, C.D. Point-of-care controls for nosocomial legionellosis combined with chlorine dioxide potable water decontamination: A two-year survey at a Welsh teaching hospital. J. Hosp. Infect. 2005, 61, 100-106. [CrossRef]

35. Kusnetsov, J.; Torvinen, E.; Perola, O.; Nousiainen, T.; Katila, M.L. Colonization of hospital water systems by legionellae, mycobacteria and other heterotrophic bacteria potentially hazardous to risk group patients. APMIS Acta Pathol. Microbiol. Immunol. Scand. 2003, 111, 546-556. [CrossRef]

36. Allegheny County Health Department. Approaches to Prevention and Control of Legionella Infection in Allegheny County Health Care Facilities, 2nd ed.; Allegheny County Health Department: Pittsburgh, PA, USA, 1997; pp. 1-15.

37. Clancy, C.M.; Department of Veterans Affairs; Veterans Health Administration. VHA Directive 1061: Prevention of Healthcare-Associated Legionella Disease and Scald Injury from Potable Water Distribution Systems; Veterans Health Administration: Washington, DC, USA, 2014.

38. Vickers, R.M.; Brown, A.; Garrity, G.M. Dye-containing buffered charcoal yeast extract medium for the differentiation of members of the family Legionellaceae. J. Clin. Microbiol. 1981, 13, 380-382.

39. ISO. Water Quality—Detection and Enumeration of Legionella. In International Organization for Standardization; ISO 11731: Geneva, Switzerland, 1998; pp. 1-16.

40. ISO. 11731-2:2004 Water Quality Detection and Enumeration of Legionella Part 2: Direct Membrane Filtration Method for Waters with Low Bacterial Counts; ISO: Geneva, Switzerland, 2004.

41. Eaton, E.; Rice, E.; Baird, R. (Eds.) Standard Methods for the Examination of Water and Waste Water; American Public Health Association: Washington, DC, USA, 2005.

(C) 2019 by the authors. Licensee MDPI, Basel, Switzerland. This article is an open access article distributed under the terms and conditions of the Creative Commons Attribution (CC BY) license (http://creativecommons.org/licenses/by/4.0/). 